\title{
Side-Specificity of Olfactory Learning in the Honeybee: Generalization between Odors and Sides
}

\author{
Jean-Christophe Sandoz and Randolf Menzel ${ }^{1}$ \\ Freie Universität Berlin, Institut für Biologie-Neurobiologie, D-14195 Berlin, Germany
}

\begin{abstract}
Honeybees (Apis mellifera) can be trained to associate an odor stimulus with a sucrose reward. The neural structures involved in the detection and integration of olfactory stimuli are represented bilaterally in the brain. Little is known about the respective roles of the two sides of the brain in olfactory learning. Does each side learn independently of the other, or do they communicate, and if so, to what extent and at what level of neural integration? We addressed these questions using the proboscis extension response (PER) conditioning paradigm applied in a preparation that allows the separation of the two input sides during olfactory stimulations. Bees conditioned to two odorants $\mathrm{A}$ and $\mathrm{B}$, one being learned on each side ( $+\mathrm{H}+\mathrm{B}+$ training), showed in extinction tests rather unspecific responses: They responded to both odorants on both sides. This could be attributable to either a transfer of the learned information between sides, or to a generalization between odorants on each side. By subjecting bees to conditioning on one side only (A+/0 training), we found that the learned information is indeed transferred between sides. However, when bees were trained explicitly to give opposite values to the two odorants on the two sides $(\mathrm{A}+\mathrm{B}-\mathrm{B}+\mathrm{A}-$ training), they showed clear side-specific response patterns to these odorants. These results are used in the elaboration of a functional model of laterality of olfactory learning and memory processing in the honeybee brain.
\end{abstract}

Most sensory systems are bilaterally symmetrical and provide the nervous system with both redundant and side-specific information. Determining redundancy and specificity of sensory input requires the detection, encoding, and storage of the input side together with the qualities of the stimulus. Because most animals' nervous systems are bilaterally organized, the connectivity between sensory organs and the nervous system may serve the function of sidedirected analysis and storage. However, sensory and cognitive functions are often represented more strongly or exclusively in only one side of the brain, although the sensory input is bilaterally symmetrical. The human brain has been studied in this respect in great detail (Springer and Deutsch 1981) and ample evidence exists for the dominance of one hemisphere over the other in the control of particular cognitive functions (e.g., speech, visual and auditory perception, spatial orientation, attention). In birds, visual learning in the context of parental imprinting (Horn 1998; Johnston and Rogers 1998) and early gustatory learning are strongly lateralized (Sandi et al. 1993, Rose 2000). In these cases the memory trace appears to be functional (or may even exist) in only one side of the brain, and in visual learning the laterality of learning and memory formation may reach such

${ }^{1}$ Corresponding author.

E-MAIL menzel@neurobiologie.fu-berlin.de; FAX 49-30-83855455.

Article and publication are at http://www.learnmem.org/cgi/doi/ $10.1101 / \mathrm{lm} .41401$. an extreme form that only one eye is involved in learning and memory retrieval (Güntürkün et al. 1989; Vallortigara 2000). Such unilateral visual preferences have also been shown in a number of animal species, including fish (Miklsi et al. 2001), toads (Vallortigara 2000), and sheep (Peirce et al. 2000).

In the honeybee (Apis mellifera), several works studied the laterality of memory. Unilateral memory storage was suggested for tactile and olfactory stimuli (Masuhr and Menzel 1972; Erber et al. 1997), whereas visual stimuli (colors) were already shown to be transferred between sides (Masuhr and Menzel 1972). In olfaction, bees that had learned an odor stimulus with only one antenna were found to be unable to recognize this stimulus with the other antenna, and to learn this stimulus with the other antenna more slowly than during initial learning. Such observations were made in free-flying bees (Masuhr and Menzel 1972) and in harnessed bees trained in PER (proboscis extension response) conditioning (Macmillan and Mercer 1987). The results were interpreted to indicate a close connection between the odor stimulus and the input side rather than as an effect of a unilateral memory trace. The interpretation referred to the proposal by Forel (1910) and von Frisch (1967) of a "topochemical sense", meaning that any odor is a "right odor" or a "left odor" depending on the input side. This notion was corroborated by Martin (1965) who showed side-specific turning behavior to learned unilateral odor stimuli. Neither of these former studies, however, ad-

LEARNING \& MEMORY 8:286-294 @ 2001 by Cold Spring Harbor Laboratory Press ISSN1072-0502/01 \$5.00

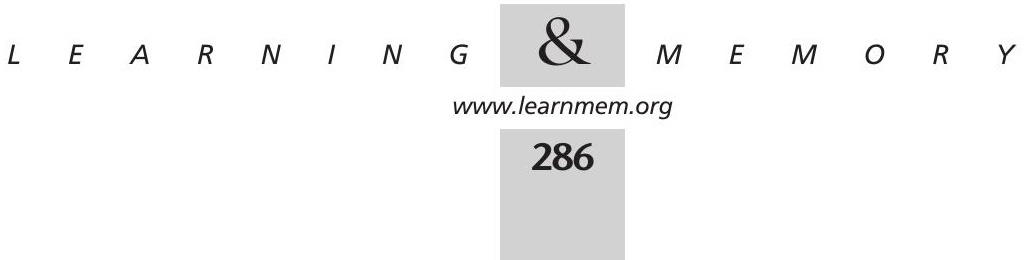


dressed the question of side-specific localization of the olfactory memory trace.

More recently, Thorn and Smith (1997) proposed that the phenomenon of blocking in learning odor mixtures requires the input from both antennae (for a detailed discussion of the existence of the blocking phenomenon in honeybees, see Gerber and Ullrich [1999] and Hosler and Smith [2000]), and thus possibly both sides of the brain. It is conceivable that the memory trace in the brain is distributed between both sides of the brain. In this case, the sensory compound of odor and side is the relevant stimulus stored in memory, and a "right odor" is perceptually different from a "left odor". However, until now no work has directly addressed this possibility. In particular, two important aspects of laterality in olfactory learning processes have not yet been studied sufficiently : (1) side-specificity of the unconditioned stimulus (US - in this case the reward value of sucrose solution) pathway and (2) side-specificity of the conditioned stimulus (CS - here odor stimuli) pathway. The question of side-specificity of the US is addressed in an accompanying paper (J.C. Sandoz, M. Hammer, and R. Men$z e l$, in prep). Here we focussed on the side-specificity of the CS pathway. Using two odors, we trained bees in different schedules in which we varied the side of odor presentations during learning and testing. We show contralateral retrieval of memories established by unilateral conditioning as well as the ability of bees to give opposite values to the same odor between sides.

\section{RESULTS}

\section{Experiment 1: Learning One Odor on Each Side (A+/B+ Training)}

Bees that learned two different odors showed good learning performances on the two sides $(n=30)$, starting with $20 \%-$ $23 \%$ responses and reaching $77 \%$ at the third conditioning trial (Fig. 1A). No difference appeared in the learning performances between the right and left side (log linear analysis, partial and marginal association $\chi^{2}<1.1$, NS). Tests after $3 \mathrm{~h}$ showed a rather unspecific response pattern with respect to the two odorants (Fig. 1B): Responses to the odors were not only high on the rewarded side (odor A on the right; odor B on the left: response rates 90\%-93\%) but also on the opposite side (response rates: 70\%-90\%). A statistical difference appeared between responses, due to a lower response to odor B on the right side (Cochran's Q test, $\mathrm{Q}=10.5, \quad P<0.05$; pairwise comparisons involving responses to B-right: $\mathrm{S}>6.8, P<0.05)$. Learning two odorants, one on each side, leads to unspecific responses: The two sides respond to both odorants. Two hypotheses can be put forward: (1) a transfer of the learned information takes place between sides, i.e., bees respond to odor A on the B+
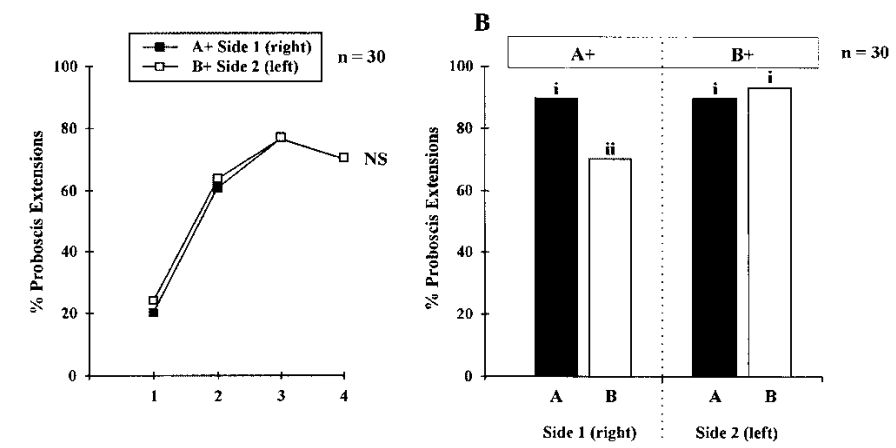

Figure 1 (A) Proboscis extension responses by honeybees during conditioning to two different odors on the two sides ( $\mathrm{A}+\mathrm{B}+$ training). Responses developed identically on both sides, eventually reaching $\sim 75 \%$ responses (NS: nonsignificant, log-linear analysis). (B) Bees' performances during the test phase after $A+/ B+$ training. Bees show an unspecific response pattern, reponding with a high rate $(>70 \%)$ to both odors on both sides. Different letters indicate significantly different levels of responses (pairwise comparisons after Cochran's Q test).

side because the memory template of A was bilaterally transferred and is now present on this side (and vice versa); or (2) bees generalize between odorants on a single side, i.e., they respond to odor $\mathrm{A}$ on the $\mathrm{B}+$ side not because it is odor A, but because it is perceptually similar to odor B, which was learned on this side. The next experiment evaluates the two options.

\section{Experiment 2: Learning One Odor on One Side (A+/0 Training)}

Bees learned the CS efficiently on both sides, starting with $0 \%-7 \%$ responses and reaching $50 \%-68 \%$ at the fourth conditioning trial (Fig. 2A). No difference appeared in the learning performances between the right $(n=25)$ and the left side $(n=28, \log$ linear analysis, partial and marginal association $\chi^{2}<0.6$, NS). In the test phase (Fig. 2B), bees showed gradients of responses depending on the odor and on the side tested (Cochran's $Q$ test, $Q=39.1, P<0.001$; all pairwise comparisons: $S>11.9, P<0.01)$ : They responded with the highest probability to odor $A$ on the trained side (75\%) and with the lowest probability to odor B (a novel odor in this case) on the untrained side (26\%). Most interestingly, bees responded more to odor A on the untrained side (58\%) than to odor B (novel) on the trained side (38\%). These results show that both transfer of information between sides (hypothesis 1) and generalization between odors on one given side (hypothesis 2) take place. However, the bilateral transfer appears to have a higher impact than generalization because responses to A on the contralateral side were higher than responses to $\mathrm{B}$ on the conditioning side.

\section{Experiment 3: Differential Conditioning ( $A+B-/ 0$ and $A+/ B-$ Training)}

Bees that were subjected to a differential conditioning pro-

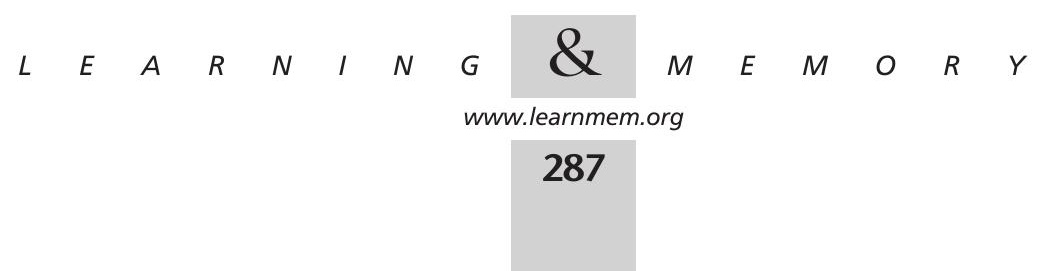




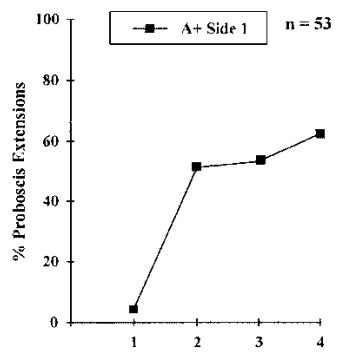

B

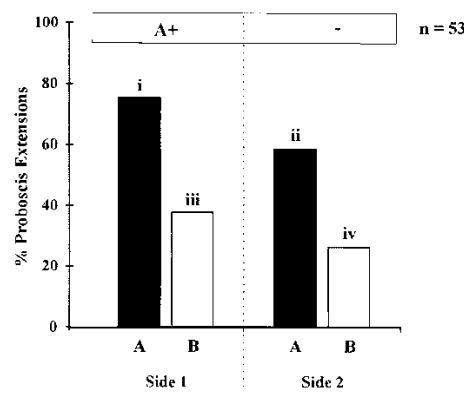

Figure 2 Bees' performances $(A)$ in a unilateral olfactory conditioning procedure $(A+/ 0$ training); $(B)$ in the test phase after $3 \mathrm{~h}$ retention. Bees responded most strongly to odor $A$ on the trained side and the least to odor $B$ (novel odor) on the untrained side. Note that bees responded more to odor $A$ on the untrained side than to odor B on the trained side. This shows that both transfer of information between sides and generalization between odors on one given side take place. However, transfer appears to have a higher impact than generalization, because responses to $\mathrm{A}$ on the contralateral side were higher than responses to $\mathrm{B}$ on the conditioning side. Different letters indicate significantly different levels of responses (pairwise comparisons after Cochran's Q test).

cedure on one side $(\mathrm{A}+\mathrm{B}-/ 0$ training; Fig 3A) learned to respond to odor A (69\%-72\% at CS+ trial 3) and not to odor B (from $21 \%$ down to $0 \%$ at CS- trial 4) without any difference between sides $(n=28$ on both sides, log linear analysis on responses to CS+ or to CS-, partial and marginal associations in all cases: $\chi^{2}<3.3$, NS). Responses in the test phase (Fig. 3B) showed a clear pattern with a significant heterogeneity (Cochran's $Q$ test, $Q=56.8, P<0.001$ ). Bees responded almost exclusively to odor $\mathrm{A}$ and at a higher rate on the trained side (86\%) than on the untrained side (66\%). All pairwise comparisons were significant $(S>8.1, P<0.05)$ except between responses to odor $B$ on each side $(S=1.6$, NS).

Bees subjected to a differential conditioning procedure

A
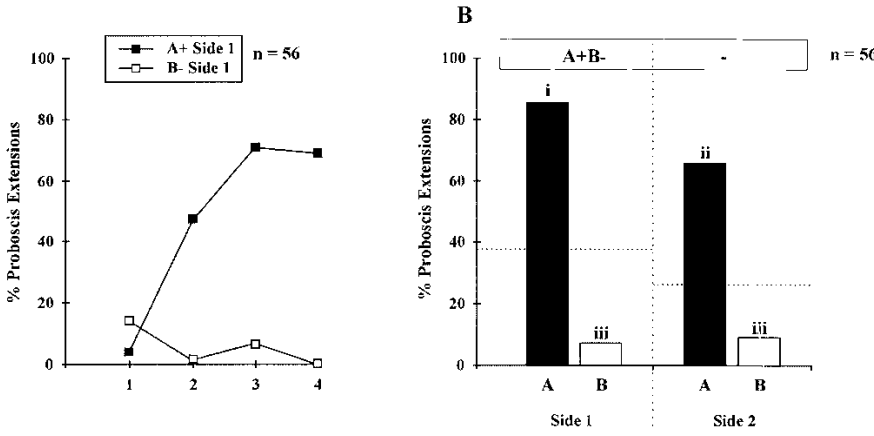

Figure 3 Bees' performances $(A)$ in a unilateral differential conditioning procedure $(\mathrm{A}+\mathrm{B}-/ 0$ training); $(B)$ in the test phase after $3 \mathrm{~h}$ retention. As before, honeybees transferred information about odor $A$ to the opposite side. Responses to odor B were low on both sides. Comparing these results to those of Figure $2(A+/ 0$ training, see dotted line), responses to $B$ appear to be inhibited on both sides, suggesting a transfer of inhibitory information between sides. Different letters indicate significantly different levels of responses (pairwise comparisons after Cochran's Q test). where the CS+ and CS- were presented on opposite sides (A+/B- training; Fig. 4A) also learned the task (reaching $52 \%-71 \%$ for $\mathrm{A}$, responses staying $<5 \%$ for B) but showed faster learning on the left side than on the right side ( $\mathrm{n}=21$ in both cases, log linear analysis, partial association $\chi^{2}=7.4, P<0.01$, marginal association $\left.\chi^{2}=6.6, P<0.01\right)$. Separate CS+ curves for each side (broken lines) are shown in Fig 4A. CScurves were identical on both sides. Nevertheless, this result had no impact on responses in the test phase, with both groups giving identical response patterns (log linear analysis, partial and marginal association $\chi^{2}<2.7$, NS). Responses in the test phase (Fig. 4B) also showed a clear pattern with a significant heterogeneity (Cochran's $Q$ test, $Q=49.1$, $P<0.001$; all pairwise comparisons were significant: $\mathrm{S}>8.3, P<0.05)$. As before, bees responded to odor A on both sides, but with a higher probability on the trained side (74\%) than on the untrained side (55\%). Responses to B were low on both sides, but with significantly fewer responses on the side where B was explicitly unrewarded (5\%) as on the contralateral side (where A was rewarded: 21\%).

The patterns of responses recorded after $24 \mathrm{~h}$ were nearly identical to those observed after $3 \mathrm{~h}(\mathrm{~A}+\mathrm{B}-/ 0$ training: on Side $1, A=76 \%$ and $B=6 \%$ responses; on Side $2=A$ $66 \%$ and $B=9 \%$ responses; $A+/ B-$ training: on Side 1 , $A=83 \%$ and $B=21 \%$ responses; on side $2=A 66 \%$ and $\mathrm{B}=0 \%$ responses).

In differential conditioning procedures, with the CS+ and $\mathrm{CS}-$ presented either on the same side $(\mathrm{A}+\mathrm{B}-/ 0$ training; Fig. 3B) or on opposite sides (A+/B-training; Fig. 4B), responses to $B$ are inhibited in comparison to a situation where $B$ is not explicitly unrewarded $(A+/ 0$ training; see Fig. 2B and dotted lines in Figs. 3B and 4B). This suggests that the information concerning the $\mathrm{CS}+$ as well as the CS- is transferred between sides.

\section{Experiment 4: Inverted Differential Conditioning $(A+B-/ B+A-$ Training)}

Bees conditioned in an inverted differential conditioning procedure $(\mathrm{A}+\mathrm{B}-/ \mathrm{B}+\mathrm{A}-$ training) learned to respond to each odor on one side only (Fig. 5A). Responses to the CS+ started at a rate of $6 \%-16 \%$ (trial 1) and reached 58\%-61\% (trials 5-6). In contrast, responses to the CS- started at 13\%-29\% and decreased to $<4 \%$. The tendency for faster learning on the left side was not significant (log linear analysis, partial and marginal association $\chi^{2}<2.4$, NS), whereas the difference between performances to CS+ and CS- was highly significant (log linear analysis, partial association $\chi^{2}=127.7, P<0.001$, marginal association $\left.\chi^{2}>125.5, P<0.001\right)$. In the test phase (here after a $24 \mathrm{~h}$ retention interval; Fig. 5B), the

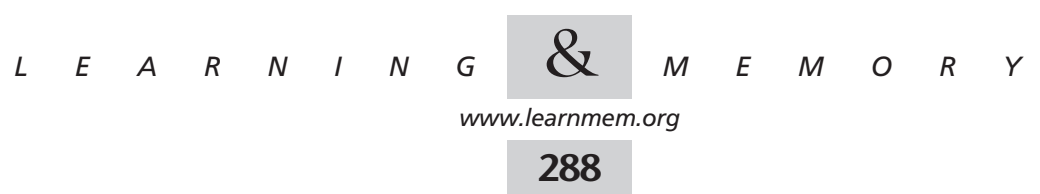


response pattern was very distinctive (Cochran's $Q$ test, $\mathrm{Q}=48.4, P<0.001$; all pairwise comparisons between responses to odor A or odor B between sides were significant: $\mathrm{S}>22.7, P<0.05$; comparison between B-right and A-left was at the threshold of significance, $\mathrm{S}=7.6$ (threshold 7.8). Bees responded preferentially to the CS+ of each side (to odor A on the right side, and to odor $\mathrm{B}$ on the left side). Bees are thus able to learn to give opposite values to two odors on the two sides.

\section{DISCUSSION}

Our experiments on the laterality of the CS in honeybee olfactory learning showed that: (1) Bees conditioned to two different odors on the two sides produced rather unspecific response patterns, responding to both odors on both sides; (2) when conditioned to an odor on only one side, bees responded after a retention period of $3 \mathrm{~h}$ to this odor on both sides. Excitatory as well as inhibitory information appeared to be shared between sides; and (3) when explicitly trained, bees learned opposite discrimination patterns at the two sides.

\section{Localization of the Olfactory Memory Trace}

Until now, numerous studies on the learning and memory performance of bees have been carried out using a bilateral CS input (for review, see Menzel 1999, 2001). Much knowledge has been acquired about the brain structures involved in the integration, retention, and retrieval of olfactory information. Two main structures, the antennal lobes (ALs) and the mushroom bodies (MBs) are thought to contain the olfactory memory trace (Hammer and Menzel 1998). These structures are represented bilaterally in the brain and it is still unclear how the structures of the two sides interact. Applying unilateral CSs, our study shows that, after a period of retention, bees can respond to a CS on the contralateral side. This suggests that both sides of the brain share information about the learned odor. Two models of the functional organization of the olfactory memory may explain such a result: After conditioning with a unilateral CS, either (1) the memory trace is limited to one side and information is accessed contralaterally during retrieval, or (2) the memory trace is distributed on both sides and retrieval is achieved ipsilaterally (or both ipsilaterally and contralaterally). In invertebrates, one-sided memory storage is known, for example, in the slug Limax maximus. In this species, the two sides were even shown to inhibit each other during retrieval (Teyke et al. 2000). In the honeybee, amnestic treatments have suggested otherwise (Erber et al. 1980): Bees unilaterally conditioned to an odor and subjected shortly thereafter to a localized cooling of the ipsilateral or of
A
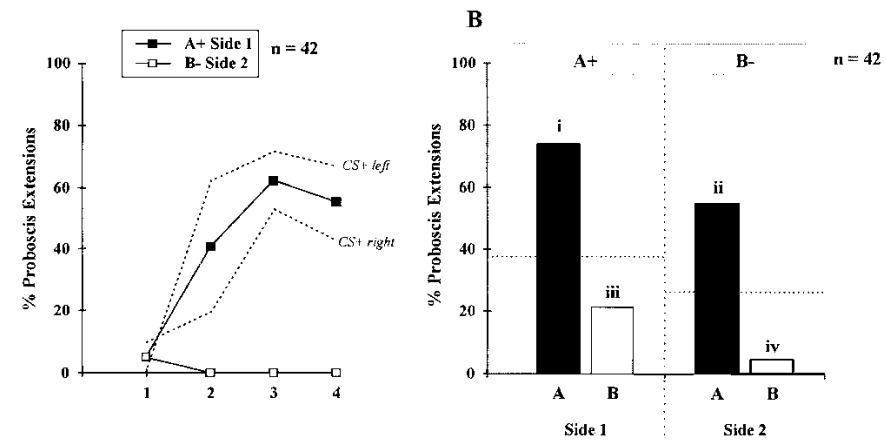

Figure 4 Bees' performances $(A)$ in a bilateral differential conditioning procedure $(A+/ B-$ training). In this case, conditioning performances were significantly higher on the left than on the right side, so acquisition curves are shown for each side (broken lines); $(B)$ in the test phase after $3 \mathrm{~h}$ retention. As before, honeybees transfer information about odor $\mathrm{A}$ to the opposite side. Responses to odor $B$ are on both sides lower than in Figure $2(A+/ 0$ training, see dotted line) although bees responded more on Side $1(\mathrm{~A}+$ side) than on Side $2(\mathrm{~B}-$ side). Different letters indicate significantly different levels of responses (pairwise comparisons after Cochran's Q test).
A

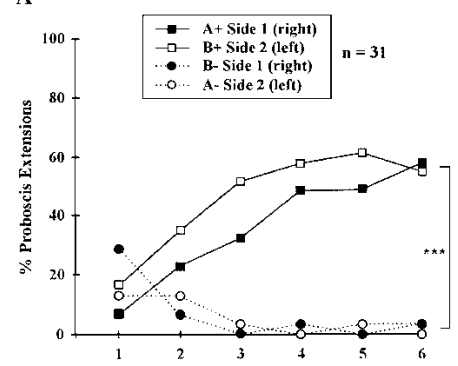

the contralateral calyx regions of the MBs showed in both cases reduced performances in a later test. This suggested that the calyx regions on both sides are involved in the formation of the olfactory memory. By applying localized electrical brain stimulations on either the ipsilateral or the contralateral $\alpha$-lobe of the MBs, Sugawa (1986) induced similar retrograde amnestic effects. Whereas experimental amnestic treatments produced an amnesia in these two parts of the MBs over periods of several minutes, similar treatments applied to the antennal lobes interfered with the memory trace only on the ipsilateral side and only within a short time after learning $(<1 \mathrm{~min})$. This indicates that only the ipsilateral antennal lobes may be involved in establishing a lasting memory, and this within a very short period of time (Menzel et al. 1990). Because the MBs in the two brain sides are intimately connected neuroanatomically (Mobbs

Figure 5 Performances of bees in an inverted differential conditioning procedure $(A+B-B+A-$ training). $(A)$ During the conditioning phase, responses to each odor increase on the side where it is rewarded, and decrease on the side where it is explicitly unrewarded (***: $P<0.001, \log$-linear analysis comparing responses to CS+ and CS-). (B) During the test phase, bees show a clear side-specific pattern of responses. Different letters indicate significantly different levels of responses (pairwise comparisons after Cochran's Q test).

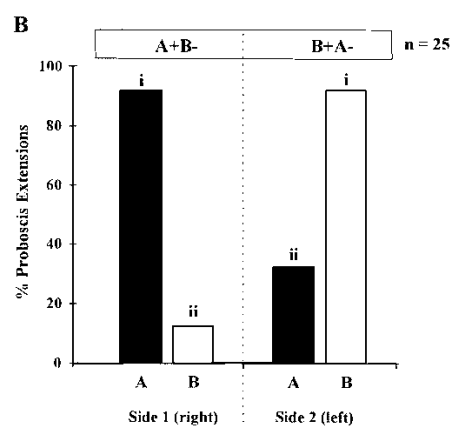


1984), but the antennal lobes appear anatomically separated (Arnold et al. 1985), it appears likely that an associative experience with a unilateral odor CS is first processed unilaterally at the level of the ALs, but then some kind of bilateral processing may take place at the level of the MBs. The major connections identified between the sides are located at the level of the mushroom bodies: A number of bilateral neurons interconnect the ipsilateral $\alpha$-lobe to the contralateral $\alpha$-lobe and protocerebral lobe through two tracts, the $\alpha$-lobe-to- $\alpha$-lobe tract (Rybak and Menzel 1993) and the anterior-median-protocerebral-commissure (Mobbs 1982, 1984). However, no direct connections have yet been reported between the calyces of both sides, and although carefully addressed, no feedback neurons were found that connect the ipsilateral $\alpha$-lobe and the contralateral calyx region (Grünewald 1999). Although not all bilateral connections of the bee brain have yet been described, it is conceivable that it is through interconnections at the level of the $\alpha$-lobes that the two hemispheres interact to produce a bilateral olfactory memory trace, or to solve higher-order processing tasks like blocking (Thorn and Smith 1997). Recent findings emphasize the need to study such connections at the functional level. After chemical ablations of parts of the mushroom bodies, Scheiner et al. (2001) found that bees that had the two median calyces ablated performed simple tactile learning like normal bees whereas reversal learning was clearly affected. Interestingly, in such bees, bilateral connections are abnormal, with the MBs occasionally fusing at the level of the B-lobes (Malun and Moseleit 1999).

\section{Bilateral Retrieval and Inverted Differential Conditioning}

If the olfactory memory trace is indeed localized on both sides, then why have a number of studies (Masuhr and Menzel 1972; Macmillan and Mercer 1987; Sandoz et al., in prep.) found side-specific responses, possibly indicative of low information transfer between the two sides of the brain? The MBs are multisensory neuropils that receive highly processed input from the olfactory as well as from the visual and mechanosensory modalities. The memory trace in the MBs needs time to develop whereas memory in the AL appears to be directly accessible (Hammer and Menzel 1998). The consolidation process during the time window of several minutes after the learning trial may be predominantly controlled by the MBs and may lead to functional connections between the different sensory modalities, thus integrating the newly learned olfactory information to contextual cues and forming a multisensory configural memory (Menzel 1999). Both the importance of context stimuli in the consolidation or retrieval of olfactory memories (Gerber and Smith 1998; Gerber and Menzel 2000) as well as the capacity to form configural associations (Chandra and Smith 1998; Deisig et al. 2001) have been documented recently. We hypothesize that the information about the side on which a CS was presented could be part of the contextual information stored in such configural memories. In this case, the presentation on the contralateral side of an odor learned ipsilaterally would in fact depend on a generalization process: The odor is the same, but contextual stimuli (like the side) are different. The amount of generalization is therefore controlled by other context-related stimuli present during retrieval. In the studies cited, two main facts could explain a low transfer: First, to provide unilateral CSs, several studies either masked one antenna with a cosmetic paste (Masuhr and Menzel 1972), or with a plastic cover (Macmillan and Mercer 1987d Thorn and Smith 1997) and/or cut off an antenna (Masuhr and Menzel 1972; Macmillan and Mercer 1987). In all cases, the bees received via the masked antenna, constant mechanical and/ or gustatory stimulations whose effects on learning, retrieval, and generalization are unknown. Such context stimuli could have reduced the bilateral retrieval effect. In our study, we also had nonsymmetrical context stimuli, because a syringe was present on only one side during training so that a visual/mechanical context stimulus was lacking on the contralateral side. In some experiments, bees received such context stimuli on only one side $(\mathrm{A}+/ 0$ or $\mathrm{A}+\mathrm{B}-/ 0$ trainings), but in others they had the same number of such "context presentations" on both sides $(\mathrm{A}+\mathrm{B}+, \mathrm{A}+\mathrm{B}-$, $\mathrm{A}+\mathrm{B}-/ \mathrm{B}+\mathrm{A}-$ trainings). Comparing these situations, no difference appeared in the amount of bilateral transfer observed. However, in future studies we will try to control such context stimuli and will be using a stimulation system providing a continuous airflow on both sides, in which odor stimuli can be applied independently on one side or the other.

The second explanation of a low transfer is that in parallel to context asymmetries, other factors could be involved in studies showing a lack of bilateral transfer. In most of the cited studies, tests of performance on the contralateral side were carried out rather soon after unilateral odor conditioning: Macmillan and Mercer (1987), $15 \mathrm{~min}$; Thorn and Smith (1997), 10 min; Sandoz et al. (J.C. Sandoz, M. Hammer, and R. Menzel, in prep.), 9 min; however, Masuhr and Menzel (1972), $2 \mathrm{~h}$. If the bilateral MB memory trace needs time to develop as we think it does, whereas the strictly olfactory AL memory is directly accessible, it is possible that the bees' responses were predominantly controlled by AL memory shortly after learning. Because this memory may be only unilaterally represented, retrieval of learned odor would thus be low on the contralateral side. However, when bees are tested with longer retention times (after 3 or $24 \mathrm{~h}$, as in our study) a bilateral memory would have established itself and could be retrieved from both sides.

We obtained a transfer from one side to the other in all experiments except Experiment 4, in which bees were

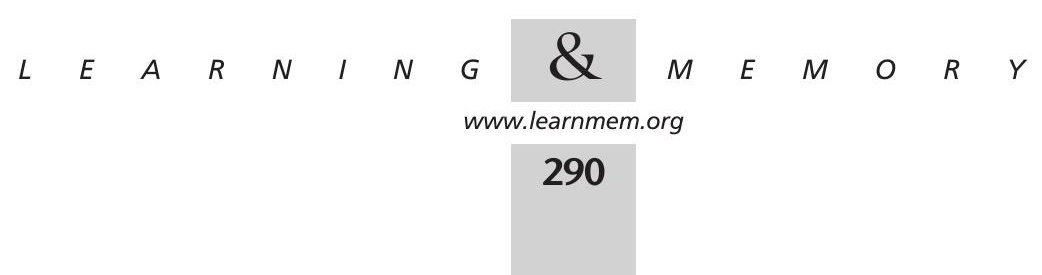


trained to give opposite values to two given odors on the two sides. If bilateral transfer takes place, how do bees learn to respond contrarily when a CS is presented on one side or on the other? According to our hypothesis, information about the side of the CS is part of contextual stimuli that are stored in a configuration with the olfactory memory. Thus it is logical to expect that this "side" information can become more salient in some situations than in others: for example, if naturally more salient cues, like odors, lose their predictive value for the reward. This was the case in Experiment 4, where two odors, A and B, were each presented with a reward half of the time and without the rest of the time. In this case, only the configuration odor-side could allow the bees to respond correctly. They had to learn that "odor A on the right side" is rewarded, but not "odor A on the left side". Thus, bees needed to learn not to transfer and to give a higher priority to the "side" information. The fact that the acquisition rate of the two CS+ in Experiment 4 (Fig. 5A) was lower than in experiments where no contrary information was given (Experiments 1, 2, and 3) could reflect the difficulty of the task bees had to solve. As the design of the $\mathrm{A}+\mathrm{B}-\mathrm{B}+\mathrm{A}-$ procedure in Experiment 4 corresponded to two $\mathrm{A}+\mathrm{B}-/ 0$ procedures, each applied on one side $(\mathrm{A}+\mathrm{B}-/ 0$ and $0 / \mathrm{B}+\mathrm{A}-$ ), it could mean that already during the acquisition phase of Experiment 4, the two sides did not learn fully independently. In this case, the learning of side-specific olfactory information would be a kind of higher-order learning phenomenon that could be extremely useful for bees performing close-range orientation in mixed-species flower patches and could explain the observations of Martin (1965) who showed a side-specific turning behavior to odor stimuli learned in a particular spatial arrangement.

In summary, the bilateral transfer phenomenon appears to be both time-dependent (because it develops over time) and event-dependent (because its appearance seems to depend on certain training procedure parameters). Both the event- and time-dependency of bilateral transfer will be explicitly addressed in future work.

\section{Neural Substrates of Bilateral Transfer}

Further work should focus on making a closer link between the observed transfer phenomena and the neural structures of the brain. In particular, our hypothesis that the memory trace remains unilateral in the ALs, but becomes bilateral in the MBs, will have to be tested. One possible technique is to study odor-evoked activity in these structures using optical imaging (Galizia et al. 1997; Joerges et al. 1997). In the ALs, odorants appear to be coded according to spatio-temporal activity patterns in the glomeruli (Galizia et al. 1999; Sachse et al. 1999). As these patterns appear to be modified by conditioning (Faber et al. 1999), the next step of our work will be to follow the responses of the morphologically identified glomeruli between the two ALs of bees previously conditioned in an $\mathrm{A}+/ 0$ training. If our hypothesis is correct, changes should be observed on one side only. Using the same technique, odor-evoked activity has been recorded in the lip region of the mushroom bodies (Faber and Menzel in press) and recordings at the $\alpha$-lobe level are also possible (Faber 1999). However, no topographical organization of odor activity has as yet been proven in either structure, and changes induced by learning are not fully understood. Future work will first have to focus on activity modifications inherent to conditioning before the exploration of bilateral memory transfer can begin. Another technique may also shed light on this question. Chemical ablations of the mushroom bodies (Malun 1998) have already been used to assess their role in tactile (Scheiner et al. 2001) and olfactory learning (D. Malun and M. Giurfa, pers. comm.). Results appear to show that simple forms of learning are not affected by ablations, whereas more complex forms are. We will use this method to check whether unilateral or bilateral MB ablations are deleterious for bilateral transfer processes.

In conclusion, our work suggests that the development of the olfactory memory in bees, in particular its bilateral transfer, is a time- and event-dependent phenomenon. In a companion paper, we studied the impact of the side of US input on the characteristics of the memory trace (J.C. Sandoz, M. Hammer, and R. Menzel, in prep). We found that a US applied only at the level of one antenna produces unilateral sensitization, whereas a US given to the proboscis, or to both one antenna and the proboscis induce bilateral sensitization. Also, bees could learn an odor CS with all three kinds of US (antenna, proboscis, antenna + proboscis), but with a proboscis US, new learning appeared to be inhibited on the contralateral side. This work suggests that the proboscis US in an antenna + proboscis US (which is the normal US in a natural foraging situation) probably plays the role of a "bilateral" confirmation of what was experienced on one side (antenna US). Olfactory learning tasks in a natural foraging situation are known to provide spatially organized stimuli (both odors and nectar sources) whose arrangement bees could have to learn to efficiently find food sources. To fully understand how bees learn odors and how they utilize such learning in adapting their behavior to foraging, more emphasis on the side-specificity of learning phenomena is necessary.

\section{MATERIALS AND METHODS}

\section{Honeybees and Separation of the Olfactory Space}

Worker bees were collected in the morning at the entrance to an outdoor hive, immobilized by short cooling, and fixed in metal harnesses with strips of tape placed behind the head and between the thorax and abdomen. To separate the olfactory input space of the bee into two independent zones, we used thin plastic walls placed between the two antennae. The walls were made of a 40 $\mathrm{mm} \times 50 \mathrm{~mm}$ piece of overhead transparency plastic, in which the shapes of the bee holder and of the bee's head were cut precisely

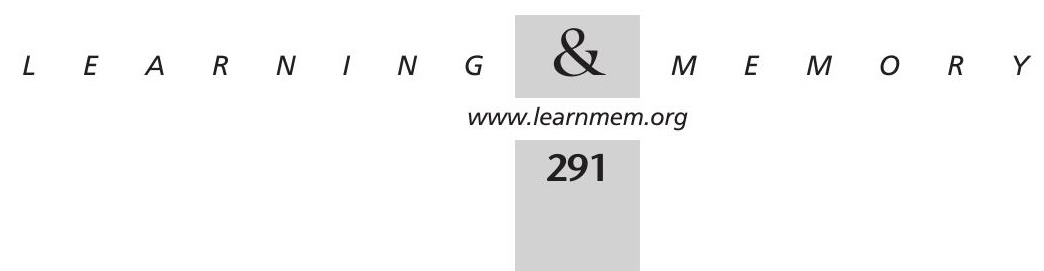




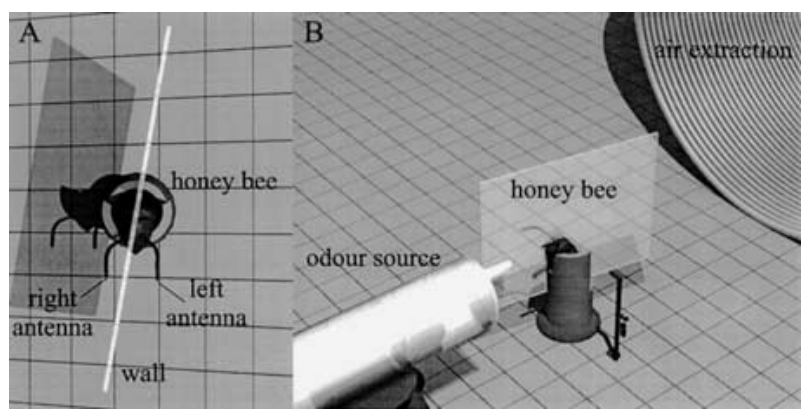

Figure 6 Separation of olfactory input sides using thin plastic walls waxed onto the head. (A) Honeybee placed in a holder with a wall between the two antennae. The wall is placed slightly to one side to allow the proboscis to move freely. (B) Odor stimulations are provided on one side of the wall. An exhaust vent placed behind the bee ensures a laminar flow along the wall.

so as to fit snugly and to prevent any contact between sides. Each wall was then attached with low-temperature melting wax to close any remaining spaces between sides, respectively under the proboscis to the front, on the head, and on the back of the tube. The wall was placed slightly to one side, so that the proboscis could move freely (Fig. 6A). In all experiments, and on every experimental day, there were as many bees with the walls placed to the left of the proboscis as with walls placed to the right. Bees were then left for $2 \mathrm{~h}$ before conditioning began so that they could habituate to the presence of the walls.

\section{Stimulation Apparatus}

For each conditioning or test trial, a bee was placed facing a holder to which two syringes could be attached (Fig. 6B). During odor stimulations, one syringe at a time was placed on the holder, with its outlet on the side of the separation wall that was to be stimulated. The odorant from the syringe was released parallel to the wall and directed toward the bee's antenna. An exhaust vent $10 \mathrm{~cm}$ behind the bee ensured that the flow on each side of the wall was laminar and that all released odors were vented out of the experimental room.

\section{Stimuli}

Two odors were used as CS. Limonene and 1-hexanol (Sigma-Aldrich Chemicals), which were utilized in previous studies of olfactory learning in bees, are known to provide high performance levels and to be easily discriminated by bees (Gerber and Ullrich 1999; see also Fig 3A). Five microliters of pure compound were soaked on a $1 \mathrm{~cm}^{2}$ piece of filter paper that was inserted into a $20 \mathrm{~mL}$ syringe. As US, a 30\% w/w sucrose solution was used.

\section{PER-Conditioning}

\section{Rewarded (CS-US) Trials}

Bees were put into the apparatus one at a time. After $15 \mathrm{sec}$ of familiarization to the overall experimental context, the odor CS was presented to the bee for $6 \mathrm{sec}$ on one side. During the first $3 \mathrm{sec}$ of odor presentation, the occurrence of a proboscis extension was noted by the experimenter. Three seconds after onset of the CS, the antenna placed on the same side was stimulated with the US, leading to a proboscis extension. The bee was then rewarded for 3 sec by food uptake at the proboscis. Thus, in the experiments reported here the US consisted of antennal and proboscis stimula- tion and of an uptake of sucrose solution via the proboscis (we call this a "compound US" as compared to isolated antennal or proboscis USs as they are studied in J. Sandoz, M. Hammer, and R. Menzel, in prep.).

\section{Test Trials}

These were unrewarded (CS only) extinction trials: The CS was presented on one side without any stimulation with the US and the experimenter noted the occurrence of a proboscis extension.

\section{Protocols}

\section{Conditioning Phase}

Bees were subjected to different kinds of conditioning procedures where two odors, A and B, were either rewarded or unrewarded, and presented either on one side or the other. In every experiment, and every experimental day, limonene was odor A for $50 \%$ of the bees and odor B for the other 50\% (vice versa for 1-hexanol). Details of conditioning procedures are given separately for each experiment and are summarized in Table 1. In all experiments, the role of the sides was balanced between animals, so that every day as many bees received a given stimulation pattern on the left side as on the right side.

\section{Test Phase}

Bees were subjected to a test procedure after a retention time, where odors A and B were presented once on each side. The retention time was $3 \mathrm{~h}$ in Experiments 1-3. The test phase of Experiment 3 was performed again after $24 \mathrm{~h}$, and nearly identical results as those displayed in Figures $3 \mathrm{~B}$ and $4 \mathrm{~B}$ were obtained. Because Experiment 4 induced a long-lasting conditioning procedure, we decided to test these bees after $24 \mathrm{~h}$. The four odor presentations were carried out in a random order. The intervals between test trials were $10 \mathrm{~min}$.

\section{Experiment 1: Learning One Odor on Each Side ( $A+/ B+$ Training)}

Bees received eight conditioning trials (10 min intertrial intervals), four trials with odor $\mathrm{A}$ on the right side, and four with odor $\mathrm{B}$ on the left side. Trials with each odor were pseudorandomized in an AB$B A B A A B$ or BAABABBA order. The test phase was carried out after $3 \mathrm{~h}$ retention.

\section{Experiment 2: Learning One Odor on One Side (A+/0 Training)}

To investigate whether excitatory learning information learned on

Table 1. Stimulations Carried Out on Each Side During Conditioning

\begin{tabular}{cll}
\hline Experiment & Side 1 & Side 2 \\
\hline 1 & $\mathrm{~A}+$ & $\mathrm{B}+$ \\
2 & $\mathrm{~A}+$ & 0 \\
3 & $\mathrm{~A}+\mathrm{B}-$ & 0 \\
& $\mathrm{~A}+$ & $\mathrm{B}-$ \\
4 & $\mathrm{~A}+\mathrm{B}-$ & $\mathrm{B}+\mathrm{A}-$ \\
\hline
\end{tabular}

Odors A and B were presented either as rewarded (+) or unrewarded $(-)$. " 0 " indicates that this side received no stimulation during conditioning.

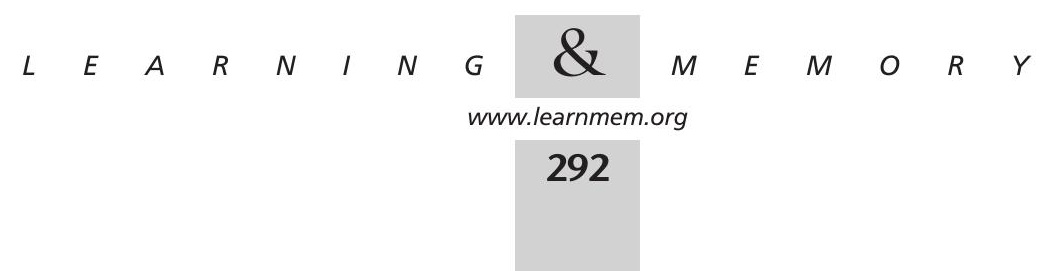


one side of the brain may be transferred to the other side, we subjected bees to a procedure in which an odor is trained on only one side. Bees received four conditioning trials (10 min intertrial intervals) with odor A, either on the right or on the left side. The test phase was carried out after $3 \mathrm{~h}$ retention.

\section{Experiment 3: Differential Conditioning ( $A+B-/ 0$ and $A+/ B-$ Training)}

To evaluate a possible bilateral transfer of information acquired by inhibitory training, two groups of bees were subjected to differential conditioning procedures with odor A rewarded and B unrewarded. In one group, A and B were presented on the same side; in the other group, A and B were presented on opposite sides. A and $B$ trials were pseudorandomized in an ABBABAAB or BAABABBA order. Intertrial intervals were of $10 \mathrm{~min}$.

\section{Experiment 4: Differential Conditioning $(A+B-/ B+A-$ training)}

This experiment was designed to test whether bees may use the two sides of the brain independently. Odors A and B were each rewarded on one side and unrewarded on the other side. On the right side, bees received six rewarded trials with odor $\mathrm{A}$ and six unrewarded trials with odor B. On the left side, they had six rewarded trials with odor B and six unrewarded trials with odor A. Every second stimulation was performed on one given side. On each side, A and B stimulations were provided in a pseudorandomized order: ABBABAABABBA or BAABABBABAAB. Bees thus received a total of 24 trials at $5 \mathrm{~min}$ intertrial intervals $(10 \mathrm{~min}$ between stimulations on the same side).

\section{Statistics}

Comparisons between sides of the performances during the conditioning phase were made using a log-linear analysis performed on the frequencies of bee responses at each trial. Interactions of the design variables (successive trials, conditioning side) with the development of odor-evoked PER was considered significant only if both partial and marginal association $\chi^{2}$ were significant $(P<0.05)$. Responses during the test phase were compared using Cochran's $Q$ test which allows one to compare $n$ dichotomous variables within groups. It was complemented, when significant, with pairwise comparisons following the Marascuilo and McSweeney method (1967, in Zar [1999]). Different Roman numerals in the figures (i, ii, iii, or iv) indicated significant differences in these pairwise comparisons.

\section{ACKNOWLEDGMENTS}

We thank T. Franke for his help with the experiments and the art of Figure 6. We are grateful to C.G. Galizia for stimulating ideas at the initiation of this project. Thanks to M. Wurm for her help polishing the English expression. J.-C.S. was funded by a research fellowship from the Alexander von Humboldt Foundation. The research of R.M. is supported by the Deutsche Forschungsgemeinschaft.

The publication costs of this article were defrayed in part by payment of page charges. This article must therefore be hereby marked "advertisement" in accordance with 18 USC section 1734 solely to indicate this fact.

\section{REFERENCES}

Arnold, G., Masson, C., and Budharugsa, S. 1985. Comparative study of the antennal lobes and their afferent pathway in the worker bee and the drone (Apis mellifera). Cell Tissue Res. 242: 593-605.

Chandra, S. and Smith, B.H. 1998. An analysis of synthetic processing of odor mixtures in the honeybee. J. Exp. Biol. 201: 3113-3121.

Deisig, N., Lachnit, H., Hellstern, F., and Giurfa, M. 2001. Configural olfactory learning in honeybees: Negative and positive patterning discrimination. Learn. Mem. 8: 70-78.

Erber, J., Masuhr, T., and Menzel, R. 1980. Localization of short-term memory in the brain of the bee, Apis mellifera. Physiol. Entomol. 5: 343-358.

Erber, J., Pribbenow, B., Grandy, K., and Kierzek, S. 1997. Tactile motor learning in the antennal system of the honeybee (Apis mellifera L.). J. Comp. Physiol. A. 181: 355-365.

Faber, T. 1999. 'Veränderung der neuronalen Repräsentation von Düften im Gehirn der Biene durch Lernen.' Ph.D. thesis, Freie Universität Berlin, Berlin, Germany.

Faber, T. and Menzel, R. 2001. Visualizing a mushroom body response to a conditioned odor in honeybees. Naturwissenschaften (in press).

Faber, T., Joerges, J., and Menzel, R. 1999. Associative learning modifies neural representations of odors in the insect brain. Nature Neurosci. 2: $74-78$.

Forel, A. 1910. Das Sinnesleben der Insekten. Reinhardt, Munich.

von Frisch, K. 1967. The dance language and orientation of bees, Harvard University Press, Cambridge, MA.

Galizia, C.G. and Menzel, R. 2001. The role of glomeruli in the neural representation of odours: Results from optical recording studies. $J$. Insect Physiol. 47: 115-129.

Galizia, C.G., Sachse, S., Rappert, A., and Menzel, R. 1999. The Glomerular code for odor representation is species specific in the honeybee Apis mellifera. Nature Neurosci. 2: 473-478.

Gerber, B. and Smith, B.H. 1998. Visual modulation of olfactory learning in honeybees. J. Exp. Biol. 201: 2213-2217.

Gerber, B. and Ullrich, J. 1999. No evidence for olfactory blocking in honeybee classical conditioning. J. Exp. Biol. 202: 1839-1854.

Gerber, B. and Menzel, R. 2000. Contextual modulation of memory consolidation. Learn. Mem. 7: 151-158.

Grünewald, B. 1999. Morphology of feedback neurons in the mushroom body of the honeybee, Apis mellifera. J. Comp. Neurol. 404: 114-126.

Güntürkün, O., Emmerton, J., and Delius, J.D. 1989. Neural asymmetries and visual behaviour in birds. In Biological signal processing (ed. H.C. Lüttgau and R. Necker), pp. 122-145, Deutsche Verlagsgesellschaft, Weinheim.

Hammer, M. and Menzel, R. 1998. Multiple sites of associative odor learning as revealed by local brain microinjections of octopamine in honeybees. Learn. Mem. 5: 146-156.

Horn, G. 1998. Visual imprinting and the neural mechanisms of recognition memory. TINS 21: 300-305.

Hosler, J.S. and Smith, B.H. 2000. Blocking and the detection of odor components in blends. J. Exp. Biol. 203: 2797-2806.

Joerges, J., Küttner, A., Galizia, C.G., and Menzel, R. 1997. Representation of odours and odour mixtures visualized in the honeybee brain. Nature 387: 285-288.

Johnston, A.N. and Rogers, L.J. 1998. Right hemisphere involvement in imprinting memory revealed by glutamate treatment. Pharmacol. Biochem. Behav. 60: 863-871.

Macmillan, C.S. and Mercer, A.R. 1987. An investigation of the role of dopamine in the antennal lobes of the honeybee, Apis mellifera. J. Comp. Physiol. A. 160: 359-366.

Malun, D. 1998. Early development of mushroom bodies in the brain of the honeybee Apis mellifera as revealed by BrdU incorporation and ablation experiments. Learn. Mem. 5: 90-101.

Malun, D. and Moseleit, A. 1999. Hydroxyurea-induced morphological changes in the olfactory pathway of the honeybee Apis mellifera. Proceedings of the First Göttingen Conference of the German Neuroscience Society, 32.

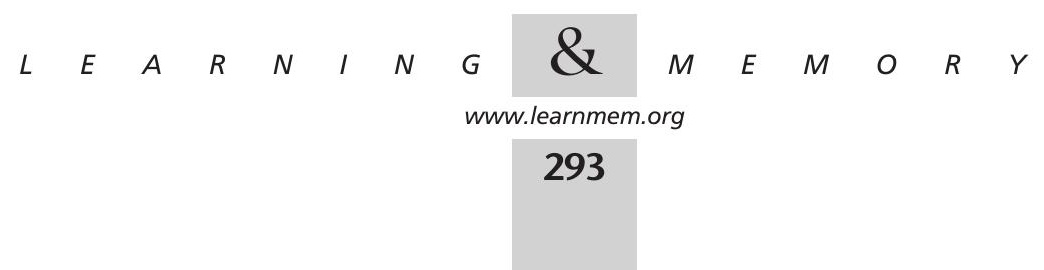


Martin, H. 1965. Leistungen des topochemischen Sinnes bei der Honigbiene. Z. vergl. Physiol. 50: 254-292.

Masuhr, T. and Menzel, R. 1972. Learning experiments on the use of side specific information in the olfactory and visual system in the honeybee (Apis mellifica). In Information processing in the visual systems of arthropods (ed. R. Wehner), pp. 315-322. Springer, Berlin.

Menzel, R. 1990. Learning, memory, and 'cognition' in honey bees. In Neurobiology of comparative cognition (ed. R.P. Kesner and D.S. Olton), pp. 237-292. Erlbaum Inc., Hillsdale, NJ.

. 1999. Memory dynamics in the honeybee. J. Comp. Physiol. A. 185: 323-340.

- 2001. Searching for the memory trace in a mini-brain, the honeybee. Learn. Mem. 8: 53-62.

Miklsi, A., Andrew, R.J., and Gasparini, S. 2001. Role of right hemifield in visual control of approach to target in zebrafish. Behav. Brain Res. 122: 57-65.

Mobbs, P.G. 1982. The brain of the honeybee Apis mellifera I. The connections and spatial organization of the mushroom bodies. Phil. Trans. R. Soc. Lond. B 298: 309-354.

. 1984. Neural networks in the mushroom bodies of the honeybee. J. Insect Physiol. 30: 43-58.

Peirce, J.W., Leigh, A.E. , and Kendrick, K.M. 2000. Configurational coding, familiarity and the right hemisphere advantage for face recognition in sheep. Neuropsychologia 38: 475-483.

Rose, S.P.R. 2000. God's organism? The chick as a model system for memory studies. Learn. Mem. 7: 1-17.

Rybak, J. and Menzel, R. 1993. Anatomy of the mushroom bodies in the honey bee brain: The neuronal connections of the alpha-lobe. J. Comp. Neurol. 334: 444-465.
Sachse, S., Rappert, A., and Galizia, C.G. 1999. The spatial representation of chemical structures in the antennal lobe of honeybees: Steps towards the olfactory code. Europ. J. Neurosci. 11: 3970-3982.

Sandi, C., Patterson, T.A., and Rose, S.P.R. 1993. Visual input and lateralization of brain function in learning in the chick. Neurosci. 52: 393-401,

Scheiner, R., Weiß, A., Malun, D., and Erber, J. 2001. Responsiveness to sucrose and side-specific tactile antennal learning in honey bees (Apis mellifera) with partial mushroom-body ablations. Anim. Cogn. 3: $227-235$.

Springer, S.P. and Deutsch, G. 1981. Left brain, right brain. W.H. Freeman and Co, San Francisco.

Sugawa., M. 1986. 'Zeitliche Dynamik und Lokalisation des Engramms im Honigbienengehirn (Apis mellifera). ' Diplom. thesis, Freie Universität, Berlin, Germany.

Teyke, T., Wang, J.W., and Gelperin, A. 2000. Lateralized memory storage and crossed inhibition during odor processing by Limax. J. Comp. Physiol. A. 186: 269-278.

Thorn, R.S. and Smith, B.H. 1997. The olfactory memory of the honeybee Apis mellifera, III. Bilateral sensory input is necessary for induction and expression of olfactory blocking. J. Exp. Biol. 200: 2045-2055.

Vallortigara, G. 2000. Comparative neuropsychology of the dual brain: A stroll through animals' left and right perceptual worlds. Brain \& Lang. 73: 189-219.

Zar, J. H. 1999. Biostatistical Analysis. Prentice Hall International, London, UK.

Received May 30, 2001; accepted in revised form August 8, 2001. 


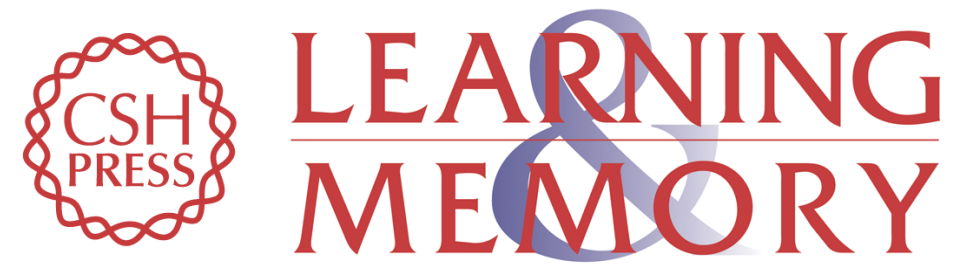

\section{Side-Specificity of Olfactory Learning in the Honeybee: Generalization between Odors and Sides}

Jean-Christophe Sandoz and Randolf Menzel

Learn. Mem. 2001, 8:

Access the most recent version at doi:10.1101//m.41401

References This article cites 31 articles, 11 of which can be accessed free at: http://learnmem.cshlp.org/content/8/5/286.full.html\#ref-list-1

License

Email Alerting Receive free email alerts when new articles cite this article - sign up in the box at the Service top right corner of the article or click here. 